\title{
Association between left atrial phasic conduit function and early atrial fibrillation recurrence in patients undergoing electrical cardioversion
}

\author{
Anna Degiovanni ${ }^{1}$. Enrico Boggio ${ }^{1}$ Eleonora Prenna ${ }^{1}$. Chiara Sartori ${ }^{1} \cdot$ Federica De Vecchi ${ }^{1} \cdot$ Paolo N. Marino ${ }^{1}$. \\ From the Novara Atrial Fibrillation (NAIF) Study Group
}

Received: 2 August 2017 / Accepted: 23 November 2017 / Published online: 27 November 2017

(c) The Author(s) 2017. This article is an open access publication

\begin{abstract}
Background Diastolic dysfunction promotes atrial fibrillation (AF) inducing left atrial (LA) remodeling, with chamber dilation and fibrosis. Predominance of LA phasic conduit (LAC) function should reflect not only chamber alterations but also underlying left ventricular (LV) filling impairment. Thus, LAC was tested as possible predictor of early AF relapse after electrical cardioversion (EC).

Methods 96 consecutive patients, who underwent EC for persistent non-valvular AF, were prospectively enrolled. Immediately after successful EC ( $3 \mathrm{~h} \pm 15 \mathrm{~min})$, an echocardiographic apical four-chamber view was acquired with transmitral velocities, annular tissue Doppler and simultaneous LV and LA three-dimensional full-volume datasets. Then, from LA-LV volumetric curves we computed LAC as: [(LV maximum - LV minimum) - (LA maximum - LA minimum) volume], expressed as \% LV stroke volume. LA pump, immediately post-EC, was assumed and verified as being negligible. Sinus rhythm persistence at 1 month was checked with ECG-Holter monitoring.

Results At 1 month 62 patients were in sinus rhythm and 34 in AF. AF patients presented pre-EC higher Elé values $(p=0.012)$, no major LA volume differences $(p=\mathrm{NS})$, but a stiffer LV cavity $(p=0.012)$ for a comparable LV capacitance $(p=0.461)$. Conduit contributed more $(p<0.001)$ to $\mathrm{LV}$ stroke volume in $\mathrm{AF}$ subpopulation. Multiple regression revealed LAC as the most significant AF predictor $(p=0.013)$, even after correction for biometric characteristics and pharmacotherapy $(p=0.008)$.

Conclusion Our data suggest that LAC larger contribution to LV filling soon after EC reflects LA-LV stiffening, which skews atrioventricular interaction leading to AF perpetuation and makes conduit dominance a powerful predictor of early AF recurrence.
\end{abstract}

Keywords Left atrial conduit function $\cdot$ Full-volume 3D echocardiography $\cdot$ Atrial fibrillation $\cdot$ Electrical cardioversion

Presented in part at the 64th Annual Scientific Sessions of the American College of Cardiology, Chicago, April 2-4, 2016.

Electronic supplementary material The online version of this article (https://doi.org/10.1007/s00392-017-1188-9) contains supplementary material, which is available to authorized users.

Paolo N. Marino

paolo.marino@maggioreosp.novara.it

1 Department of Translational Medicine, Clinical Cardiology, Università del Piemonte Orientale, Azienda Ospedaliera Universitaria "Maggiore della Carità", Corso Mazzini 18, 28100 Novara, Italy

\section{Introduction}

Atrial fibrillation (AF) is one of the most frequent arrhythmias and one of the major causes of stroke, heart failure and cardiovascular morbidity worldwide [1].

It develops in 1 out of 4 middle-age adults in Europe and its prevalence continues to grow [2,3]. Even in the ablation era, electrical cardioversion (EC) remains a quick and effective method to convert AF to sinus rhythm [4]. Because most patients exceed $48 \mathrm{~h}$ or longer AF initiation, in most cases, EC needs to be scheduled after at least 3-week anticoagulation. In this period, pre-treatment with antiarrhythmic drugs can improve efficacy and facilitate EC [5].

Until nowadays there have been no strong predictors that allow physicians to identify the AF patient in whom 
to attempt EC with an acceptable probability of subsequent sinus rhythm maintenance. On this topic, a lot of various data among ECG measurements, echocardiographic parameters and biomarkers have been proposed, but no method has demonstrated good predictability so far [6, 7].

Some authors have suggested that atrial phasic function assessment can stratify the risk of AF post-EC [8]. This is further substantiated by the fact that (1) we know the potential relationship existing between risk of $\mathrm{AF}$ and a predisposing condition such as LV diastolic dysfunction [9] and (2) that the atrial conduit contribution to LV filling has been shown to be in direct relation with the degree of the underlying LV diastolic impairment in heart failure patients [10].

In this study, we demonstrate the existence of a strong association between the conduit contribution to LV filling volume, as computed with 3D echocardiography, and the arrhythmia recurrence in a group of patients with persistent $\mathrm{AF}$ and recent $\mathrm{EC}$.

\section{Methods}

\section{Patients' population}

After appropriate informed consent in agreement with institutional human review studies committee guidelines and local IRB approval, we enrolled prospectively 96 consecutive patients who underwent EC for persistent non-valvular AF. Patients younger than 18 years, with mitral prosthesis or severe mitral regurgitation and patients who did not respond to EC were, per protocol, excluded. To minimize possible bias related to various cycle duration differences during AF, patients were imaged few hours after successful EC, in regular sinus rhythm. During subsequent clinical followup all patients underwent clinical survey and a 24-h Holter ECG recording at 1 month, with AF recurrence defined as symptomatic or asymptomatic episode of atrial arrhythmia (>30 s, registered AF or flutter or atrial tachycardia on ECG or Holter examination) causing cardiology consultation. The characteristics of the patients' population (subdivided according to AF recurrence within 1 month) are reported in Table 1, identified by comorbidities and treatment in addition to conditions comprised within the CHA2DS2VASc score. We also reported other potential important clinical situations as described by Deng et al. [11] as part of new scores proposed for AF. All cardiovascular chronic therapy and in particular antiarrhythmic drugs were started, for all patients, after an appropriate anticoagulation period one week before scheduled EC.

\section{Echocardiographic examination}

Transthoracic echocardiography data were acquired after successful EC ( $3 \mathrm{~h} \pm 15 \mathrm{~min}$ ) using a Vivid E9 (GE Medical Systems, Horten, Norway) system with both a 2D probe (average frame rate 65 frame/s) and a $4 \mathrm{~V}$ probe for $3 \mathrm{D}$ acquisition (average $30 \mathrm{frame} / \mathrm{s}$ ). We used apical fourchamber and two-chamber gray-scale and color views, with pulsed and continuous mitral flow velocity tracings. An apical four-chamber tissue Doppler acquisition was also obtained, together with a triplane apical LV volumetric view using the $4 \mathrm{~V}$ transducer.

At the end of the standard examination, a multi-beat (at least five consecutive cardiac cycles) pyramidal 3D echocardiographic full-volume dataset was acquired from the apex in each patient. The volume data was displayed in real-time, two orthogonal apical views and three crosssectional slices, with optional volume rendering techniques for visualization of valves and structures. Fullvolume acquisition was obtained during held respiration, with dataset sector (frame rate ranging between 20 and 40 frames/s) dimensions and depth set to include both the ventricle and the atrium, assuring volume sampling rates between 15 and 25/s [10].

Subsequently, using a commercially available software package (EchoPAC PC version BT112, GE Healthcare), each view was aligned to the standard apical views, using the positions of the mitral annulus plane and of the apex as markers. Initialization was done at end-diastole (ED), using two clicks in each view (apex and mitral annulus plane), with contouring and 3D surface detection automatically drawn. Once completed for ED, the same procedure was used for ES, with LV endocardial border tracked throughout the entire cardiac cycle. Surface 3D detection was automatically triggered, and if necessary, the detected 3D surface was edited manually by adding landmark points. After both ED and ES images were finalized, full 4D surface detection was performed. The same procedure was followed for LA chamber using the mitral annular plane and the roof of the cavity as reference markers [10, 12, 13]. Finally, LV and LA volumes, along with their respective time-volume curves, were derived from the triangulated surfaces by summation of all triangular patches using the divergence theorem [10].

LA longitudinal strain was assessed using a 2D speckletracking technique from standard gray-scale loops. Regional deformation of six LA segments located along the perimeter of the LA cavity was assessed in the apical four-chamber view starting from the QRS complex, with an average of six equally spaced wall segments, generally peaking in late systole, as LA peak strain. Longitudinal LV strain was also assessed from the same images which were 
Table 1 Patients' clinical characteristics and pharmacological treatment

\begin{tabular}{|c|c|c|c|}
\hline Characteristics & Total pts $($ no. $=96)$ & SR $($ no. $=62)$ & $\mathrm{AF}($ no. $=34)$ \\
\hline Age (years) & $73(67-77)$ & $72.5(66.8-76.3)$ & $73(66.8-78.3)$ \\
\hline $\mathrm{BMI}\left(\mathrm{kg} / \mathrm{m}^{2}\right)$ & $28.4 \pm 3.89$ & $28.4(25.9-30.8)$ & $28.2(25.5-31.3)$ \\
\hline CHA2DS2VASc & $3(2-4)$ & $3(2-4)$ & $3(2-4)$ \\
\hline $\operatorname{Sex}(M / F)$ & $66 / 30$ & $45 / 17$ & $21 / 13$ \\
\hline \multicolumn{4}{|l|}{ Underlined cardiopathy (no. of pts) } \\
\hline Hypertensive & 55 & 37 & 18 \\
\hline Hypertrophic & 1 & 1 & 0 \\
\hline Post-ischaemic & 3 & 3 & 0 \\
\hline Dilatative & 5 & 2 & 3 \\
\hline Mild-reduced EF & 3 & 2 & 1 \\
\hline Valvular & 4 & 3 & 1 \\
\hline No other than AF & 25 & 17 & 8 \\
\hline $\begin{array}{l}\text { AF history duration (months)- } \\
\text { unknown in } 56 \mathrm{pts}\end{array}$ & $4.9 \pm 2.9$ & $5.0 \pm 2.5$ & $4.8 \pm 2.1$ \\
\hline \multicolumn{4}{|l|}{ Oral medical treatment (no. of pts) } \\
\hline Amiodarone & 56 & 37 & 19 \\
\hline Propafenone & 13 & 10 & 3 \\
\hline Flecainide & 12 & 7 & 5 \\
\hline Sotalol & 4 & 4 & 0 \\
\hline Digoxin & 22 & 14 & 8 \\
\hline \multicolumn{4}{|l|}{ Beta-blockers } \\
\hline Bisoprolol & 47 & 31 & 16 \\
\hline Metoprolol & 4 & 4 & 0 \\
\hline Carvedilol & 4 & 2 & 2 \\
\hline Nebivolol & 7 & 3 & 4 \\
\hline Atenolol & 4 & 4 & 0 \\
\hline \multicolumn{4}{|l|}{$\mathrm{Ca}^{++}$channel blockers } \\
\hline Verapamil & 2 & 2 & 0 \\
\hline Ace inhibitors & 31 & 22 & 9 \\
\hline MRA & 20 & 13 & 7 \\
\hline VKA & 74 & 52 & 22 \\
\hline NOA & 22 & 10 & 12 \\
\hline \multicolumn{4}{|l|}{ Comorbidities (no. of pts) } \\
\hline COPD & 6 & 1 & 5 \\
\hline OSAS & 4 & 3 & 1 \\
\hline CKD $(\mathrm{GFR}<50 \mathrm{ml} / \mathrm{min})$ & 14 & 9 & 5 \\
\hline Metabolic disease & 61 & 39 & 22 \\
\hline Current smoking & 6 & 3 & 3 \\
\hline Bundle branch block & 9 & 7 & 2 \\
\hline Hypertension & 80 & 52 & 28 \\
\hline Diabetes & 19 & 12 & 7 \\
\hline
\end{tabular}

$A F$ atrial fibrillation, $F$ female, $C K D$ chronic kidney disease, $C O P D$ chronic obstructive pulmonary disease, $E F$ ejection fraction, $M$ male, $M R A$ mineralocorticoid receptor antagonist, $N O A$ new oral anticoagulants, $O S A S$ obstructive sleep apnea syndrome, $S R$ sinus rhythm, VKA Vitamin K antagonist used to evaluate LA strain and it was averaged over six segments along the ventricular septum, apex, and lateral wall [14]. An example of the echo dataset used in each patient is presented in Fig. 1.

We, then, performed an off-line analysis using a commercially available spreadsheet program to transfer data and synchronize the LA and LV volume curves as a function of time. Early after EC, patients presented regular sinus rhythm at ECG surface but with echo characteristics of atrial mechanical stunning, as could be assumed from the null or very little lateral a' peak wave at mitral 


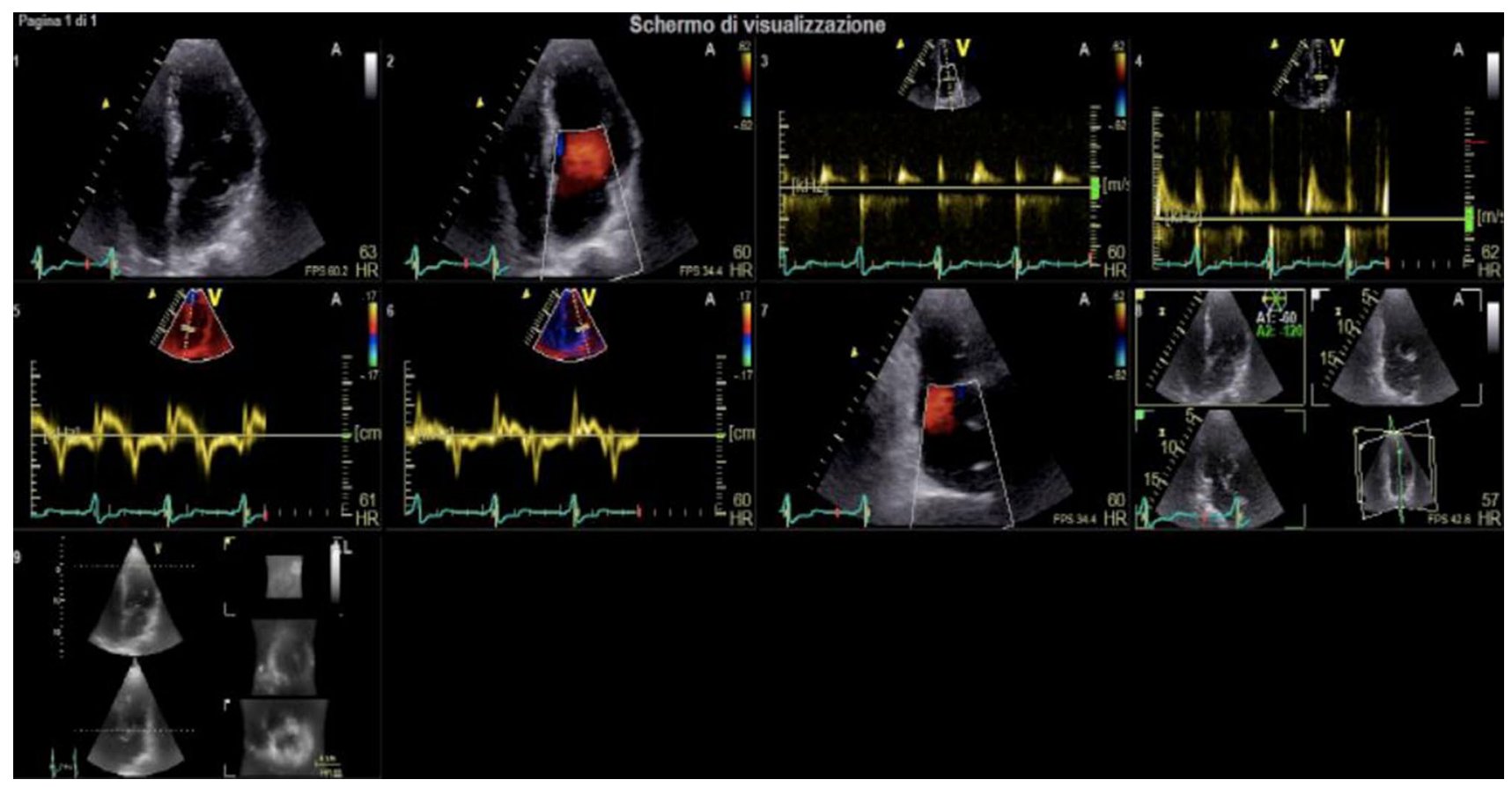

Fig. 1 Dataset of echocardiographic acquisitions. Panel of different echocardiographic acquisitions with 2D and 3D probe

tissue Doppler imaging [4 (3-5) cm/s)]. At this stage, we assumed that atrial phasic functions could be computed as reservoir: maximum LAV - minimum LAV $\left(\mathrm{LAV}_{\max }-\mathrm{LAV}_{\text {min }}\right)$,

conduit: LV stroke volume - reservoir,

considering that pump should be negligible because of atrial stunning immediately post-EC. Phasic functions were then expressed as a percent of LV stroke volume. We also evaluated total LA emptying fraction (EF), computed as $\left(\mathrm{LAV}_{\max }-\mathrm{LAV}_{\text {min }}\right) / \mathrm{LAV}_{\text {max }}$, as already described with cardiac magnetic imaging [15].

To better define ventricular diastolic properties, we used the method described by Klotz et al. [16] to assess noninvasively LV single-beat end-diastolic elastance (EDPVR) by fitting the exponential curve $\mathrm{EDP}=\alpha \times \mathrm{EDV}^{\beta}$, where $\mathrm{EDP}$ is the LV end-diastolic pressure and EDV is the end-diastolic volume, with $\alpha$ and $\beta$ as curve-fit parameters. In our population, EDV was obtained by selecting the maximum value from the 3D-full-volume LV data curve, synchronous with QRS at surface ECG, while EDP was derived using the equation $\mathrm{EDP}=11.96+0.596 \times E / e$, as proposed by Ommen et al. [17]. As already suggested by Shwarzl et al. [18], to compare the whole position of the LV EDPVR, we used the calculated $\mathrm{EDV}$ at $30 \mathrm{mmHg} \mathrm{EDP}\left(\mathrm{EDV}_{30}\right)$, as a measure of LV capacitance.

Finally, we computed LA stress, as derived from $\mathrm{LAV}_{\text {min, }}$ obtained from the time-volume curve synchronous with QRS at surface ECG, and pressure from EDP, shaping the LA cavity as with a spherical surface (thickness of the wall assumed to be $2 \mathrm{~mm}$ ) [19] according to the following formula: (stress $=1.35 \times \mathrm{EDP} \times \mathrm{LAVmin} /$ $4 \times$ wall thickness $\times(1+($ wall thickness/LAVmin $)))$ [20].

\section{Statistical analysis}

Data are expressed as mean $\pm 1 \mathrm{SD}$ or median [25th-75th confidence intervals] if data were not normally distributed. Differences between means were assessed by unpaired $t$ tests. A Mann-Whitney rank sum test was used if data were not normally distributed. A multiple logistic regression model was used to test the relationship between LA phasic conduit function, on top of other echocardiographic and biometric measurements, and early AF recurrences. Least square regression analysis was used as necessary. To find a diagnostic cut-off value of conduit for identification of short-term AF recurrence after EC, nonparametric receiver-operating characteristics (ROC) curve analyses were performed and the area under the curve showing the discriminatory ability of the cut-off variable reported. Sensitivity and specificity values of the best cut-off variable were also calculated. A $p$ value $<0.05$ was considered significant. Statistical analyses were performed using SigmaPlot version 12.5 for Windows statistical software (Jandel; San Rafael, CA, USA). 


\section{Results}

Results for the entire patients' population and after they have been subdivided according to AF recurrence within 1 month are reported in Table 2. At 1-month follow-up, 62 patients $(65 \%)$ were in sinus rhythm and $34(35 \%)$ in AF. AF patients exhibited higher LA wall stress $(p=0.002)$ and Elé $(p=0.012)$, for non-dissimilar LA volumes (maximum: $p=0.383$ and minimum: $p=0.07$ ), but a stiffer LV cavity, as documented by a higher $\beta$ value $(p=0.012)$ for a comparable capacitance ( $p=0.461$, Table 2$)$. Conduit contributed more to LV stroke volume $(p<0.001$, Table 2$)$ in the AF subpopulation. On the contrary, LA EF was lower in this subgroup $(p<0.001)$, as obviously did reservoir function (Table 2). E wave peaked higher in $\mathrm{AF}$ group $(p=0.0136)$, thus modulating a larger $E / A$ ratio, whose difference between the two sub-populations, however, did not reach statistical significance $(p=0.063)$.

Parameters significantly different at baseline between the 1 month AF versus sinus rhythm groups were used in the multiple logistic regression to test the existence of an independent predictor of AF recurrence short-term after EC. To minimize the problem of collinearity peak $\mathrm{E}$ wave value was not included, being already represented within the Elé ratio.

Results of the multiple logistic regression are shown in Table 3. Conduit was the only significant predictor of shortterm AF recurrence post-EC. Results were unmodified when patients' age, BMI, use of amiodarone or class IC drugs were included in the model (Supplementary Table 1). Using ROC curve analysis (Fig. 2), we identified a conduit value of $79 \%$ of LV stroke volume as capable of identifying those patients that will revert to AF early after EC (ROC area

Table 3 Multiple logistic regression

\begin{tabular}{lcll}
\hline Independent variable & Coefficient & Standard error & $p$ value \\
\hline Constant & -14.49 & 11.19 & 0.196 \\
LA wall stress & -0.004 & 0.032 & 0.891 \\
Elé & 0.264 & 0.178 & 0.138 \\
Conduit & 0.210 & 0.085 & 0.013 \\
LA EF & -0.189 & 0.108 & 0.081 \\
$\beta$ & -0.168 & 1.108 & 0.880 \\
\hline
\end{tabular}

$L A$ left atrial, $L A E F$ left atrial emptying fraction
Table 2 Post-cardioversion instrumental data for the entire patients' population and after it has been divided according to 1-month recurrence of $\mathrm{AF}$

\begin{tabular}{|c|c|c|c|c|}
\hline Parameters & Total pts & $\mathrm{SR}($ no. $=62)$ & $\mathrm{AF}($ no. $=34)$ & $p$ \\
\hline HR (beat/min) & $84.7 \pm 19.0$ & $80.0[71.0-99.3]$ & $82.0[70.0-95.5]$ & 0.583 \\
\hline LA stress $\left(\mathrm{g} / \mathrm{cm}^{2}\right)$ & $129.9 \pm 22.4$ & $124.8 \pm 21.6$ & $139.2 \pm 21.2$ & 0.002 \\
\hline Systolic blood pressure (mmHg) & $132.9 \pm 15.1$ & $133.8 \pm 15.3$ & $131.3 \pm 14.9$ & 0.455 \\
\hline Diastolic blood pressure $(\mathrm{mmHg})$ & $81.6 \pm 10.1$ & $81.3 \pm 10.1$ & $82.1 \pm 10.2$ & 0.723 \\
\hline Pulse pressure (mmHg) & $51.4 \pm 11.4$ & $52.6 \pm 11.9$ & $49.2 \pm 10.4$ & 0.191 \\
\hline LV EDV (ml) & $98.8 \pm 26.5$ & $96.6 \pm 26.3$ & $102.3 \pm 26.7$ & 0.344 \\
\hline $\operatorname{LV} \mathrm{EF}(\%)$ & $51.7 \pm 6.8$ & $52.3 \pm 6.3$ & $50.7 \pm 7.5$ & 0.275 \\
\hline LAV min (ml) & $52.2 \pm 16.7$ & $49.9 \pm 16.6$ & $56.4 \pm 16.3$ & 0.067 \\
\hline LAV max (ml) & $65 \pm 18.1$ & $65.5 \pm 18.8$ & $64.1 \pm 17.0$ & 0.383 \\
\hline Elé & $9.3 \pm 3.8$ & $7.43(6.26-10.32)$ & $10.27(8.27-12.0)$ & 0.012 \\
\hline$e^{\prime}(\mathrm{cm} / \mathrm{s})$ & $10.1 \pm 2.6$ & $10.19 \pm 2.60$ & $9.85 \pm 2.71$ & 0.547 \\
\hline$a^{\prime}(\mathrm{cm} / \mathrm{s})$ & $4.0(3.0-5.0)$ & $4.0(3.0-6.0)$ & $4.0(3.0-5.0)$ & 0.084 \\
\hline LA strain (\%) & $19.2 \pm 6.6$ & $19.3(15.0-22.7)$ & $17.6(13.9-21.5)$ & 0.408 \\
\hline LV strain (\%) & $-14.4 \pm 4.1$ & $-14.30 \pm 3.91$ & $-14.60 \pm 4.36$ & 0.408 \\
\hline Conduit (\%) & $76.4(68.2-81.8)$ & $72.6(62.0-76.4)$ & $84.6(79.8-89.5)$ & $<0.001$ \\
\hline Reservoir (\%) & $23.6(18.2-31.8)$ & $27.4(23.6-38.0)$ & $15.4(10.5-20.2)$ & $<0.001$ \\
\hline LA EF (\%) & $20.2 \pm 9.7$ & $22.6(18.7-24.5)$ & $11.8(9.5-16.0)$ & $<0.001$ \\
\hline $\mathrm{E}(\mathrm{cm} / \mathrm{s})$ & $88.6 \pm 25.5$ & $83.9 \pm 23.8$ & $97.2 \pm 25.7$ & 0.014 \\
\hline $\mathrm{A}(\mathrm{cm} / \mathrm{s})$ & $31(25.0-43.0)$ & $32.0(25.3-41.0)$ & $30.5(25.0-43.8)$ & 0.455 \\
\hline$E / A$ & $2.8 \pm 1.2$ & $2.4[1.8-3.2]$ & $3.1(1.9-4.3)$ & 0.063 \\
\hline$\beta(-)$ & $6.08(6.02-6.22)$ & $6.05(6.01-6.16)$ & $6.15(6.07-6.25)$ & 0.012 \\
\hline$\alpha\left(\mathrm{x} 10^{12}\right)$ & $8.9(6.0-6.2)$ & $9.7(4.1-5.3)$ & $4.4(2.3-2.9)$ & 0.058 \\
\hline LV (ml) capacitance 30 & $108.2 \pm 29.5$ & $106.5 \pm 29.5$ & $111.2 \pm 29.8$ & 0.461 \\
\hline
\end{tabular}

$A F$ atrial fibrillation, $B M I$ body mass index, $E D V$ end-diastolic volume, $E F$ ejection fraction, $H R$ heart rate, $L A$ left atrial, $L A E F$ left atrial emptying fraction, $L A V$ left atrial volume, $L V$ left ventricle, Pts patients, $S R$ sinus rhythm 


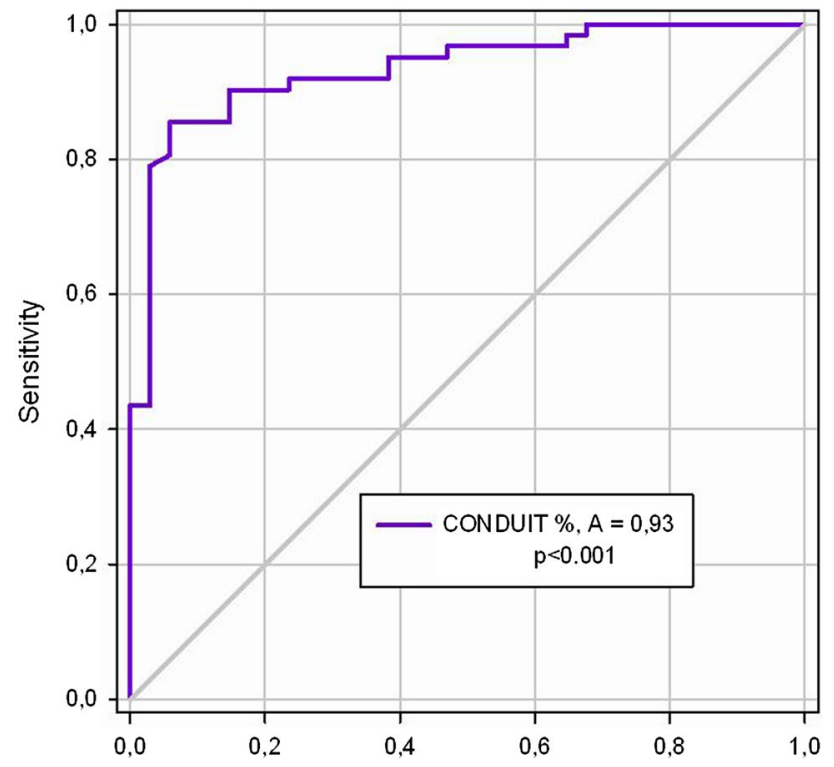

Fig. 2 ROC curve for the prediction of early arrhythmia recurrence. A conduit value of $79 \%$ of ventricular stroke volume can identify those patients that reverted to AF early after EC (ROC area 0.93 , $p<0.001$ ) with $90 \%$ sensitivity and $85 \%$ specificity

$0.93, p<0.001)$ with optimal sensitivity $(90 \%)$ and specificity $(85 \%)$.

Interobserver reproducibility for conduit has already been reported [10].

\section{Discussion}

In the present study, we observed a strong relationship between the conduit atrial phasic function and arrhythmia recurrence early after EC in patients with persistent AF. This association suggests that information obtainable from the LAC computation does provide additional insight into the mechanical characteristics of the cavity and potentially stroke risk stratifies patients post-EC [21].

It is well known that LA modulates LV filling and function in three distinct phases: as a reservoir for pulmonary venous return during ventricular systole, as a conduit from pulmonary veins directly into the LV chamber during early ventricular diastole, and as a pump that seals ventricular filling at the end of the cardiac cycle [22]. In patients with AF the booster pump function is absent, while the other two phases are modified in a reciprocal way. Thus, in the immediate post-EC period, the amount of conduit favoring ventricular filling is reflected by the reciprocal change in reservoir contributing to stroke volume. The comment is not pleonastic: the emphasis on the conduit phase in relation to AF recurrence early after EC does delineate the concomitant, underlying LV diastolic dysfunction as the fundamental condition promoting AF recurrence in our patients' population. The focus on the reservoir phase would point, instead, toward the atrial stiffening milieu as the principal cause for the recurrence of the arrhythmia [23-25].

The absence of any significant relationship, in the multivariate analysis, between the LV $\beta$ stiffness coefficient and the recurrence of the arrhythmia points, but not exclusively, in favor of the second interpretation. Previous nuclear magnetic imaging data are indeed available that associate the reservoir function to the LA enhancement in AF patients, suggesting that those with AF have more structural changes as compared with healthy volunteers [15]. Furthermore, AF is associated with different alterations in LA characteristics that permit the progression and persistence of the arrhythmia itself. We assist to an adaptation of the atrial refractory potentials and to a modification of the contractile properties with a loss of the atrial contraction (pump function) that itself promotes chamber dilatation [26]. This chamber dilation, according to the law of La Place, implies a linear increase in wall tension so as LA diameter increases atrial wall stress increases too [9].

It must also be considered that the duration of the $\mathrm{AF}$ episode may affect LA conduit function post-EC through its influence on chamber remodeling pre-EC. In this regard, we could demonstrate a significant direct linear relationship between conduit (expressed in $\mathrm{ml}$ ) and LA minimal and maximal cavity volume $(r=0.35 p<0.001$ and $r=0.23$ $p<0.03$, respectively). No relation, instead, could be demonstrated between conduit and AF duration pre-EC $(r=0.13$ $p=0.53)$. However, this can be in part due to the limited number of patients for whom the arrhythmia duration was known (27/96). For this reason, besides the unavailability of echo data post-EC, we cannot confirm or exclude a potential modification of conduit in the first few weeks after EC due to the influence of a positive chamber remodeling that may take place in that same period.

\section{Atrial phasic function, strain and volume}

Most studies on LA diastolic function have used the echocardiographic speckle-tracking technique to assess strain and indirectly assess cavity compliance [27], while other authors have investigated the atrial diastolic function by means of nuclear magnetic imaging, relying entirely on LA time-volume curve changes [28]. There are caveats for both approaches. First, if one uses speckle-tracking analysis he must accept the well-known limitation that there are regional differences in the LA segmental function during atrial contraction and relaxation. The posterior wall, in fact, exhibits the lowest strain because of the attachment of the pulmonary veins, while the inferior wall generates the highest deformation, because of its greater thickness [29]. Second, a deformation gradient is detectable from all views during atrial 
contraction and relaxation, with the generation of a higher strain at the atrioventricular junction and a lower strain in the atrial roof because this is fixed to the mediastinum [29]. Therefore, any segmental model ignoring posterior wall could overestimate global strain. Similarly, the four-chamber view of LA incorporates the interatrial septum and the area of the pulmonary veins, in which atrial strain is low. Thus, model variability is one of the possible conflicts and a major reason of such different cut-off values as reported in clinical diseases [30]. As far as LA volume curve changes are concerned, it has to be remembered that a correct assessment of the atrial phasic function from such a single time-volume curve is questionable [31].

Therefore, we think that the estimation of the cavity conduit function, expressed in term of percentage volumes that can be comprehensively obtained by simultaneous atrioventricular 3D acquisition of full-volume data sets, could better describe alteration of the atrial-ventricular coupling which characterizes the condition predisposing to AF recurrence and to document the presence and the degree of any coexistent LV diastolic dysfunction, when present.

We have already demonstrated that conduit contribution to LV filling increases with worsening of diastolic dysfunction [10] and that such parameter could be proposed for evaluation of diastole [32]. It is important to note that other authors, using cardiac computed tomography, have similarly demonstrated that diastolic dysfunction is characterized by increasing of conduit volume [33].

In our study, conduit, and obviously its reciprocal reservoir, represents a strong independent predictor of AF recurrence in a situation in which the confounding effect of the atrial booster pump function is minimized, like in the phase immediately following EC.

\section{Limitations}

Our study presents some limitations mainly represented by the short length of follow-up after EC (1 month). While recognizing the shortness of such interval we must underline the fact that most of the recurrences take place shortly after EC [34]. In any case, it would be interesting to extend the follow-up for a longer period of time to gather further confirmation of the original hypothesis, beyond the protocol so far completed.

We have chosen the time immediately after EC to acquire all the echocardiographic data, thus obviously limiting the clinical implications of our findings on the everyday clinical practice, when patients are imaged generally before EC. This was done to obtain data in regular sinus rhythm, minimizing the problem that could derive from the irregular $\mathrm{R}-\mathrm{R}$ intervals that characterize the AF condition preceding $\mathrm{EC}$ in these patients. This consideration, however, does not exclude, for the future, the idea of imaging patients before EC. As the focus of the pathophysiological reasoning relies on the atrio-ventricular coupling process, we are convinced that the variations in the R-R intervals, which characterize $\mathrm{AF}$, cannot substantially obscure the information on which the prediction is based.

This is a single-center, small-sized cohort study that needs to be reproduced and verified in a larger population possibly studied across different centers.

\section{Conclusions}

Conduit phasic function is a good descriptor of diastolic derangement relating both LA and LV volumes in particular during AF, when the pump is lost. The increment in conduit, expressed relative to LV stroke volume, and the consequent reduction in reservoir function due to the reciprocation of the two phases in our model reflects a context of increased atrioventricular stiffness, a condition prone to be a strong predictor of AF early recurrence after EC. Whether this analysis can also provide potential better stroke risk stratification in patients' post-EC will be the object of a future study.

\section{Compliance with ethical standards}

Conflict of interest All authors declared that they have no conflict of interest.

Open Access This article is distributed under the terms of the Creative Commons Attribution 4.0 International License (http://creativecommons.org/licenses/by/4.0/), which permits unrestricted use, distribution, and reproduction in any medium, provided you give appropriate credit to the original author(s) and the source, provide a link to the Creative Commons license, and indicate if changes were made.

\section{References}

1. Kirchhof P, Benussi S, Kotecha D, Ahlsson A, Atar D, Casdei B, Castella M, Diener HC, Heidbuchel H, Hendriks J, Hindricks G, Manolis AS, Oldgren J, Popescu BA, Shotten U, Van Putte B, Vardas P (2016) 2016 ESC Guidelines for the management of atrial fibrillation developed in collaboration with EACTS. Eur Heart J 37:2893-2962

2. Colilla S, Crow A, Petkun W, Singer DE, Simon T, Liu X (2013) Estimates of current and future incidence and prevalence of atrial fibrillation in the US adult population. Am J Cardiol 112:1142-1147

3. Krijthe BP, Kunst A, Benjamin EJ, Lip GY, Franco OH, Hofman A, Witteman JC, Stricker BH, Heeringa J (2013) Projections on the number of individuals with atrial fibrillation in the European Union, from 2000 to 2060. Eur Heart J 34:2746-2751

4. Mittal S, Ayati S, Stein KM, Schwartzman D, Cavlovich D, Tchou PJ, Markowitz SM, Slotwiner DJ, Scheiner MA, Lerman BB (2000) Transthoracic cardioversion of atrial fibrillation: comparison of rectilinear biphasic versus damped sine wave monophasic shocks. Circulation 101:1282-1287 
5. Kirchhof P, Andresen D, Bosch R, Borggrefe M, Meinertz T, Parade U, Ravens U, Samol A, Steinbeck G, Treszl A, Wegscheider K, Breithardt G (2012) Short-term versus long-term antiarrhythmic drug treatment after cardioversion of atrial fibrillation (Flec-SL): a prospective, randomised, open-label, blinded endpoint assessment trial. Lancet 380:238-246

6. Donal E, Lip GHY, Galderisi M, Goette A, Shah D, Marwan M, Lederlin M, Mondillo S, Edvarsen T, Sitges M, Graspa J, Garbi M, Senior R, Gimelli A, Potpara T, Van Gelder IC, Gorenek B, Mabo P, Lancellotti P, Kuck KH, Popescu BA, Hindrincks G, Habib G (2016) EACVI/EHRA Expert consensus document on the role of multi-modality imaging for evaluation of patients with atrial fibrillation. Eur Heart J Cardiovasc Imaging 17:355-383

7. O' Neal WT, Venkatesh S, Broughton ST, Griffin WF, Soliman EZ. Biomarkers and he prediction of atrial fibrillation: state of the art. Vasc Health Risk Manag 2016:12 297-303

8. Abhayaratna WP, Fatema KF, Barnes ME, Seward JB, Gersh BJ, DPhil ChB, Bailey KR, Casaclang-Verzosa G, Tsang TSM. Left atrial reservoir function as a potent marker for first atrial fibrillation or flutter in persons > 65 years of age. Am J Cardiol 2008; 101:1626-1629

9. Rosenberg MA, Manning WJ (2012) Diastolic dysfunction and risk of atrial fibrillation. A mechanistic appraisal. Circulation 126:2353-2362

10. Nappo R, Degiovanni A, Bolzani V, Sartori C, Di Giovine G, Cerini P, Fossaceca R, Kovacs SJ, Marino PN (2016) Quantitative assessment of atrial conduit function: a new index of diastolic dysfunction. Clin Res Cardiol 105:17-28

11. Deng H, Bai Y, Shantsila A, Fauchier L, Potpara TS, Lip GYH (2017) Clinical scores for outcomes of rhythm control or arrhythmia progression in patients with atrial fibrillation: a systematic review. Clin Res Cardiol 106:813-823

12. Lang RM, Badano LP, Mor-Avi V, Afilalo J, Armstrong A, Ernande L, Flachskamp FA, Foster E, Goldtein SA, Kuznetsova T, Lancellotti P, Muraru D, Picard MH, Rietzschel ER, Rudski L, Spencer KT, Tsang W, Voigt JU (2015) Recommendations for cardiac chamber quantification by echocardiography in adults: an update from the American Society of Ecocardiography and the European Association of Cardiovascular Imaging. Eur Heart J Cardiovasc Imaging 16:233-271

13. Mor-Avi V, Yodwut C, Jenkins C, Kühl H, Nesser HJ, Marwick TH, Franke A, Weinert L, Niel J, Steringer-Mascherbauer R, Freed BH, Sugeng L, Lang RM (2012) Real-time3D echocardiographic quantification of left atrial volume: multicenter study for validation with CMR. JACC Cardiovasc Imaging 5:769-777

14. Amundsen BH, Helle-Valle T, Edvardsen T, Torp H, Crosby J, Lyseggen E, Støylen A, Ihlen H, Lima JA, Smiseth OA, Slørdahl SA (2006) Noninvasive myocardial strain measurement by speckle tracking echocardiography: validation against sonomicrometry and tagged magnetic resonance imaging. J Am Coll Cardiol 4:789-793

15. Habibi M, Samiei S, Ambale Venkatesh B, Opdahl A, HelleValle TM, Zareian M, Almeida ALC, Choi EY, Wu C, Alonso A, Heckbert SR, Bluemke DA, Lima JAC (2016) Cardiac magnetic resonance-measured left atrial volume and function and incident atrial fibrillation. Results from MESA. Circ Cardiovasc Imaging 9:e004299

16. Klotz S, Hay I, Dickstein ML, Yi GH, Wang J, Maurer MS, Kass DA, Burkhoff D (2006) Single-beat estimation of end-diastolic pressure -volume relationship: a novel method with potential for noninvasive application. Am J Physiol Heart Circ Physiol 291:H403-H412

17. Ommen SR, Nishimura RA, Appleton CP, Miller FA, Oh JK, Redfield MM, Tajik AJ (2000) Clinical utility of Doppler echocardiography and tissue Doppler imaging in the estimation of left ventricular filling pressures: a comparative simultaneous Dopplercatheterization study. Circulation 102:1788-1794

18. Schwarzl M, Ojeda F, Zeller T, Seiffert M, Becher PM, Munzel T, Wild PS, Blettner M, Lackner KJ, Pfeiffer N, Beutel ME, Blankenberg S, Westermann D (2016) Risk factors for heart failure are associated with alterations of the LV end-diastolic pressurevolume relationship in non-heart failure individuals: data from a large-scale, population based cohort. Eur Heart J 37:1807-1814

19. Hunter RJ, Liu Y, Lu Y, Wang W, Schilling RJ (2012) Left atrial wall stress distribution and its relationship to electrophysiologic remodeling in persistent atrial fibrillation. Circ Arrhythm Electrophysiol 5:351-360

20. Borow KM, Green LH, Grossman W, Braunwald E (1982) Left ventricular end-systolic stress-shortening and stress-length relations in humans. Am J Cardiol 50:1301-1308

21. Biering-Sørensen T, Christensen LM, Krieger DW, Mogelvang R, Jensen JS, Højberg S, Høst N, Karlesn FM, Christensen H. Letter to the Editor. LA emptying fraction improves diagnosis of paroxysmal $\mathrm{AF}$ after cryptogenic ischemic stroke: results from the SURPRISE study. JACC Cardiovasc Imaging 2014; 7: 958-65

22. Prioli A, Marino P, Lanzoni L, Zardini P (1998) Increasing degrees of left ventricular filling impairment modulate left atrial function in humans. Am J Cardiol 82:756-761

23. Burstein B, Nattel S (2008) Atrial fibrosis: mechanisms and clinical relevance in atrial fibrillation. J Am Coll Cardiol 51:802-809

24. Tan AY, Zimetbaum $P$ (2011) Atrial fibrillation and atrial fibrosis. J Cardiovasc Pharmacol 57:625-629

25. Paulus WJ, Tschoepe C (2013) A novel paradigm for heart failure with preserved ejection fraction: comorbidities drive myocardial disfunction and remodelling through coronary microvascular endothelial inflammation. J Am Coll Cardiol 62:263-271

26. Alessie M, Ausma J, Scotten U (2002) Electrical, contractile and structural remodeling during atrial fibrillation. Cardiovasc Res $54: 230-246$

27. Kocabay G, Karabay CY, Kalaycı A, Oduncu V, Akgun T, Guler A, K1lıcgedik A, Kalkan S, İzgi A, Kırma C (2015) Left atrial function by speckle-tracking echocardiography in chronic asymptomatic alcoholic patients. Cardiovasc Toxicol 15:189-196

28. Wu V, Chyou JY, Chung S, Bhagavatula S, Axel L (2014) Evaluation of diastolic function by three-dimensional volume tracking of the mitral annulus with cardiovascular magnetic resonance: comparison with tissue Doppler imaging. J Cardiovasc Magn Reson $16: 71$

29. Vianna-Pinton R, Moreno CA, Baxter CM, Lee KS, Tsang TS, Appleton CP (2009) Two-dimensional speckle-tracking echocardiography of the left atrium: feasibility and regional contraction and relaxation differences in normal subjects. J Am Soc Echocardiogr 22:299-305

30. Rimbaş RC, Dulgheru RE, Vinereanu D (2015) Methodological gaps in left atrial function assessment by $2 \mathrm{D}$ speckle tracking echocardiography. Arq Bras Cardiol 105:625-636

31. Marino P (2010) Correct estimation of conduit function from left atrial volume curve assessment only is unlikely. J Am Soc Echocardiogr 23:1333

32. Nagueh SF, Smiseth OA, Appleton CP, Byrd BF 3rd, Dokainish H, Edvardsen T, Flachskampf FA, Gillebert TC, Klein AL, Lancellotti P, Marino P, Oh JK, Alexandru Popescu B, Waggoner AD (2016) Recommendations for the evaluation of left ventricular diastolic function by echocardiography: An update from the American Society of Echocardiography and the European Association of Cardiovascular Imaging. Eur Heart J Cardiovasc Imaging 17:1321-1360

33. Schweitzer A, Agmon Y, Aronson D, Abadi S, Mutlak D, Carasso S, Walker JR, Lessick J (2015) Assessment of left sided filling dynamics in diastolic dysfunction using cardiac computed tomography. Eur J Radiol 84:1930-1937 
34. Tielman RG, Van Gelder I, Crijns HGM, De Kam PJ, Van den Berg MP, Haaksma J, Van der Woude HJ, Alessie MA (1998) Early recurrences of atrial fibrillation after electrical cardioversion: a result of fibrillation-induced electrical remodeling of the atria? J Am Coll Cardiol 31:167-173 